\title{
Review \\ Drive and Reinforcement Circuitry in the Brain: Origins, Neurotransmitters, and Projection Fields
}

\author{
Roy A Wise*, and Ross A McDevitt' \\ I'Intramural Research Program, National Institute on Drug Abuse, National Institute on Health, Baltimore, MD, USA
}

Brain stimulation has identified two central subsets of stimulation sites with motivational relevance. First, there is a large and disperse set of sites where stimulation is reinforcing, increasing the frequency of the responses it follows, and second, a much more restricted set of sites where - along with reinforcement_-stimulation also has drive-like effects, instigating feeding, copulation, predation, and other motivated acts in otherwise sated or peaceful animals. From this work a dispersed but synaptically interconnected network of reinforcement circuitry is emerging: it includes afferents to the ventral tegmental area and substantia nigra; the dopamine systems themselves; glutamatergic afferents to the striatum; and one of two dopamine-receptor-expressing efferent pathways of the striatum. Stimulation of a limited subset of these sites, including descending inhibitory medial forebrain bundle fibers, induces both feeding and reinforcement, and suggests the possibility of a subset of fibers where stimulation has both drive-like and reinforcing effects. This review stresses the common findings of sites and connectivity between electrical and optogenetic studies of core drive and reinforcement sites. By doing so, it suggests the biological importance of optogenetic follow-up of less-publicized electrical stimulation findings. Such studies promise not only information about origins, neurotransmitters, and connectivity of related networks, by covering more sensory and at least one putative motor component it also promotes a much deeper understanding of the breadth of motivational function.

Neuropsychopharmacology (2018) 43, 680-689; doi:I0.1038/npp.20 17.228; published online I November 2017

\section{INTRODUCTION}

Early studies of the effects of electrical brain stimulation in freely moving animals identified two motivational effects. First, diencephalic stimulation at many sites can be reinforcing, controlling the acts that it reliably follows (Olds, 1956; Olds and Milner, 1954). Second, stimulation can have drive-like effects, energizing a variety of speciestypical, biologically primitive acts, such as eating, drinking, copulation, or attack, in otherwise sated or quiescent animals (Andersson and Wyrwicka, 1957; Delgado and Anand, 1953; Hess, 1957; Roberts and Carey, 1965; Wasman and Flynn, 1962). Stimulation at the same sites within the medial forebrain bundle (MFB) often has both drive-like and reinforcing effects (Caggiula and Hoebel, 1966; Margules and Olds, 1962; Mogenson and Stevenson, 1966; Roberts and Carey, 1965), whereas stimulation at a larger number of extraneous sites is reinforcing without inducing goal-directed behaviors. That rats should find stimulation reinforcing when it also makes them hungry or thirsty seemed paradoxical (Wise, 2013) and led to a range of experiments designed to explore whether the two effects were mediated by

*Correspondence: Dr RA Wise, Intramural Research Program, National Institute on Drug Abuse, National Institute on Health, 25I Bayview Boulevard, Baltimore, MD 21224, USA, Tel: +443-562-4660, E-mail: rwise@intra.nida.nih.gov

Received 21 May 2017; revised 8 August 2017; accepted 13 September 2017; accepted article preview online 6 October 2017 the same or by independent substrates (Coons and Cruce, 1968; Deutsch et al, 1962; Gratton and Wise, 1988a, b,; Huston, 1971; Mendelson, 1970). These studies have not yet identified differences between reinforcement and drive fibers. However, because electrical stimulation preferentially activates fibers of passage (Ranck, 1975), electrical stimulation studies had limited success in identifying the directly activated fibers or connections of either effect.

In the present paper we integrate these electrical stimulation findings with recent optogenetic studies that can now identify cells of origin, neurotransmitters, and synaptic targets of the stimulated fibers. These studies, taken together, begin to sketch a core structure for an integrated mesencephalic, diencephalic, and telencephalic circuitry subserving motivational function. The optogenetic study of additional structures-currently identified only by electrical stimulation -is hoped to broaden the list of anatomical substrates and to deepen our understanding of motivational function.

\section{TERMINOLOGY}

Here we separate two motivational effects of stimulation, one associated with the animal's state of mind before it earns a reward and one associated with the state of mind after the reward has been earned and is being experienced. We will use drive-like to refer to the former and reinforcing to refer to the latter. We have avoided, elsewhere in this paper, the use of the more familiar term 'reward' because it confuses the 
two meanings. The noun ('a' reward) refers to the object or effect to be sought, whereas the verb ('to' reward) refers to the action of obtaining and experiencing its effects.

Reinforcing effects are defined as the consequences of required behavior. This is measured by allowing an animal to control the stimulation. The gold standard is operant selfstimulation, where a specific response (ie, a lever-press or a nose-poke) results in a reinforcing event. In this case there is a fixed amount of reinforcement for each action. In the traditional situation, there are fixed quanta of reinforcement, and reinforcements can be counted. In the case of unsensed incentives such as earned brain stimulation, where there is no external stimulus object and continuous reinforcement can be offered (Wise, 2002), an alternative paradigm allows an animal to control both onset and offset of stimulation. This paradigm was originally called 'shuttlebox stimulation' and is referred to in the optogenetics literature as 'real-time place preference.' Care must be taken in this paradigm to differentiate between stimulus-onset effects and stimulusoffset effects; rats, having initiated the stimulation, will often work to discontinue it as if it had become aversive (Bower and Miller, 1958; Mendelson and Freed, 1973; Roberts, 1958a; Steiner et al, 1969). Furthermore, because continuous stimulation may impair the ability of the animal to remain in or return to the non-stimulation zone, locomotor artifacts can greatly influence measures in this situation. One workaround is using optogenetic stimulation where an animal is given fixed periods of stimulation or fixed periods between stimulations.

\section{SITES AND SUBSTRATES}

\section{Ventral Midbrain to Striatum}

Mesolimbic and nigrostriatal dopamine systems. Pharmacological challenge in early electrical stimulation studies suggested that the midbrain dopamine systems were a common substrate of MFB reinforcement and motivation. The reinforcing (Fouriezos and Wise, 1976; Lippa et al, 1973) and feeding-inducing (Phillips and Nikaido, 1975) effects of stimulation were each blocked by dopamine antagonists; the reinforcing effects were blocked in ways that could not be attributed to simple motor impairment (Fouriezos et al, 1978; Franklin and McCoy, 1979; Gallistel et al, 1982; Wise et al, 1978). Moreover, electrical stimulation in the region of the dopamine cell bodies was reinforcing (Crow, 1972; Routtenberg and Malsbury, 1969), and the dorsal, ventral, and lateral boundaries of the reinforcement system corresponded closely to the boundaries of the ventral tegmental area (VTA) and substantia nigra pars compacta (SNc) dopaminergic cell groups (Corbett and Wise, 1980; Wise, 1981). Subsequent paired-pulse, dual-electrode studies have revealed, however, that the directly activated fibers for both reinforcement and stimulation-induced feeding have refractory periods too short (Gratton and Wise, 1988b; Yeomans, 1979) and conduction velocities too fast (Bielajew and Shizgal, 1982; Gratton and Wise, 1988a) to be mediated directly by depolarization of dopaminergic fibers. Because the threshold for activating dopaminergic fibers within the MFB is orders of magnitude higher than what is required for brain stimulation reinforcement or stimulation-induced feeding, stimulation is now understood to activate other fibers preferentially (Gallistel et al, 1981); only very few and very local, dopaminergic fibers are activated at traditional stimulation parameters (Yeomans, 1989; Yeomans et al, 1988). Rather, the major contributions to the directly activated reinforcing effects of MFB electrical stimulation are now believed to be low-threshold, small, and descending myelinated fibers (Gallistel et al, 1981; Gratton and Wise, 1988a) one or more synapses upstream from the midbrain dopamine neurons (Wise, 1980; Yeomans, 1982).

With optogenetic methods, however, dopaminergic cell bodies of VTA or SNc can be selectively activated, and activation of these neurons is reinforcing (Ilango et al, 2014a; Ilango et al, 2014b; Kim et al, 2012; McDevitt et al, 2014; Pascoli et al, 2015; Rossi et al, 2013; Stauffer et al, 2016; Tsai et al, 2009; Wang et al, 2017; Witten et al, 2011). Two subpopulations of dopaminergic ventral midbrain neurons have been targeted-one that expresses the dopamine synthesis enzyme tyrosine hydroxylase $(\mathrm{TH})$ but includes some midline GABAergic neurons that do not release dopamine (Lammel et al, 2015; Stamatakis et al, 2013), and another that expresses the dopamine transporter but excludes some dopaminergic neurons near the midline (Darvas et al, 2014; Li et al, 2013). Stimulation of each is reinforcing (for DAT-targeted animals see Kim et al (2012) and Wang et al (2017)). The reinforcing effects of optogenetic activation of TH-expressing midbrain neurons are attenuated by ventral striatal microinjections of D1-type or D2-type dopamine antagonists (Steinberg et al, 2014). However, genetic disruption of glutamate co-release from DAT-expressing neurons does not impact their reinforcing abilities (Wang et al, 2017). Consistent with this finding, rats will lever-press for direct microinjections of D1 and D2 agonists into this brain region (Ikemoto et al, 1997). The dorsal striatum is richly innervated by dopaminergic fibers from the SNc, and stimulation of the $\mathrm{SNc}$ cell bodies produces reward measures equivalent to those produced by ventral tegmental stimulation (Ilango et al, 2014b). The other projections from these systems remain to be studied, but it has been confirmed that stimulation of dopaminergic fibers projecting to the shell of the ventral striatum is reinforcing (Steinberg et al, 2014).

VTA glutamatergic cell bodies. Glutamatergic (and GABAergic) neurons in the VTA also project to mesencephalic and cortical terminal fields. Studies testing optogenetic stimulation of VTA cell bodies in the mouse generally support a role for glutamatergic neurons in reinforcement. Stimulation of VTA cell bodies is clearly reinforcing as measured in wheel-turning, and nose-poke tasks allowing animals to earn short trains of $20-40 \mathrm{~Hz}$ stimulation (Wang et al, 2015; Yoo et al, 2016a); constant stimulation at low frequencies is aversive (Yoo et al, 2016a). Here stimulation of glutamatergic neurons resulted in many brief entrances to a stimulation chamber, whereas mice with access to dopaminergic stimulation preferred long, constant, stimulation (Yoo et al, 2016a). These findings are consistent with electrical stimulation studies suggesting that stimulation at some sites is initially reinforcing but can become aversive if left on too long (Bower and Miller, 1958; Mendelson and Freed, 1973; Roberts, 1958a; Steiner et al, 1969), further suggesting that new experiments using optogenetic stimulation should 
consider the importance of train length on a circuit-bycircuit basis. The glutamatergic neurons make local synaptic contacts onto neighboring neurons (Dobi et al, 2010) and the reinforcing effects of stimulation were blocked by local infusion of glutamate antagonists, suggesting that the reinforcing effects were mediated by those excitatory contacts.

Terminals from VTA glutamatergic neurons. Three efferent projections of VTA glutamate neurons-to ventral striatum, ventral pallidum, and lateral habenula-have been tested (Qi et al, 2016b; Root et al, 2014a; Yoo et al, 2016b). Each of these projections involves distinct, non-overlapping, populations of ventral tegmental neurons (Yoo et al, 2016a). Of these, stimulation of the VTA glutamatergic projection to the habenula is aversive. This is clearly shown in real-time and conditioned place preference paradigms, where animals avoid the position where self-controlled stimulation was given (Root et al, 2014a; Yoo et al, 2016a), reverse their preference for chambers when reinforcement contingencies are reversed, and show residual avoidance for the chamber where they most recently received stimulation (Root et al, 2014a). The aversive effect was attenuated by habenula infusions of glutamate antagonists (Root et al, 2014a). The fibers in this projection co-release glutamate and GABA but not dopamine (Root et al, 2014b; Yoo et al, 2016a) and the net effect on postsynaptic neurons, as measured electrophysiologically in vivo and in slice, is inhibitory (Root et al, 2014b; Yoo et al, 2016a).

In the case of the projection to the pallidum, the stimulation appears to be reinforcing. In this case, the stimulation was not reinforcing when given to sated animals, but food-deprived animals nose-poked for brief, highfrequency stimulations (Yoo et al, 2016a). With some electrode placements (Fulton et al, 2006; Olds, 1958a), restricted food intake augments responding for brain stimulation reward (Carr, 1996; Fulton et al, 2000). In this optogenetic study, prolonged stimulation was aversive when the animals controlled stimulation duration by entrances and exits of the chamber; the animals clearly favored short trains of stimulation (Yoo et al, 2016a).

Stimulation of projections to the ventral striatum-tested in several studies using long, constant trains of highfrequency stimulation-is aversive (Qi et al, 2016a; Yoo et al, 2016a). The aversive effects are blocked by infusion of glutamatergic or GABAergic antagonists into the ventral striatum (Yoo et al, 2016a), suggesting involvement of local GABA release. Because VTA glutamate neurons projecting to the ventral striatum show minimal coexpression of GABA synthesis enzymes (Qi et al, 2016a) and do not synaptically release GABA (Yoo et al, 2016a), this projection appears to activate a population of GABAergic neurons projecting to or within the ventral striatum. Indeed, stimulation of this pathway preferentially induces c-fos expression in parvalbumin-expressing interneurons, which project locally to medium spiny neurons and produce aversion when directly stimulated (Qi et al, 2016a). At least two populations of VTA glutamatergic neurons project to the ventral striatum: glutamate-dopamine and pure glutamate (Kawano et al, 2006; Yamaguchi et al, 2011). The glutamate-dopamine neurons synaptically target ventral striatal cholinergic interneurons
(Chuhma et al, 2014), a population of neurons that is neither rewarding nor aversive when directly stimulated (Witten et al, 2010). Accordingly, chemical lesion of dopamine terminals in the ventral striatum does not alter the aversive properties of glutamatergic pathway stimulation (Qi et al, 2016a). These results suggest that the aversive effects are selectively mediated by the pure glutamate subpopulation.

There is evidence for additional projections of VTA glutamate neurons to the prefrontal cortex and amygdala (Hnasko et al, 2012; Yamaguchi et al, 2011). Glutamatergic neurons have recently been identified within the boundaries of the SN and retrorubral field (Root et al, 2016; Yamaguchi et al, 2013). The roles of these additional glutamatergic neurons remain to be determined.

\section{Afferents to the VTA}

Lateral hypothalamus to VTA. Among the most studied reinforcement loci in the brain is the lateral hypothalamic area, which includes a bed nucleus and ascending and descending fibers of the MFB. Rats will lever-press several thousand times per hour for brief ( $0.5 \mathrm{~s}$ or less) trains of electrical stimulation at this site (Olds et al, 1960) and will do so almost continuously for tens of hours without signs of satiety (Annau et al, 1974; Olds, 1958b). At low levels the stimulation is not aversive (Hodos, 1964; Olds, 1960; Olds and Olds, 1963), but it becomes aversive when it is prolonged (Mendelson and Freed, 1973; Muenzinger and Baxter, 1957; Roberts, 1958b). The reinforcing effects are inversely related to stimulation frequency and intensity; this is a property of brain stimulation reinforcement not yet reflected in studies of optogenetic stimulation (Hodos, 1965). Nonetheless, when animals are allowed to lever-press for onset of short stimulation trains they lever-press almost continuously.

Paired-pulse electrical stimulation studies indicate that the majority of the directly activated MFB reinforcement fibers have short refractory periods (Yeomans, 1979), fast conduction velocities (Bielajew and Shizgal, 1982), project to or through the VTA (Shizgal et al, 1980), and carry reinforcement messages primarily in the rostral to caudal direction (Bielajew and Shizgal, 1986). Minority contributions appear to be made by unidentified cholinergic fibers (Gratton and Wise, 1985) and by a small number of ascending dopaminergic fibers passing very close to the electrode tip (Yeomans, 1989). One early hypothesis was that descending MFB fibers synapse on and excite VTA dopaminergic neurons (Wise, 1980); another is that the descending MFB fibers pass through the VTA, synapsing on cholinergic neurons that, in turn, relay back to the dopamine system (Yeomans, 1982). Projections to both targets remain possible.

Electrical stimulation at the same MFB reinforcement sites also induces species-typical behaviors such as eating (Delgado and Anand, 1953; Margules and Olds, 1962; Wise, 1971), drinking (Greer, 1955; Mogenson and Stevenson, 1966), gnawing (Cox and Valenstein, 1969; Roberts and Carey, 1965), nest building (Roberts and Carey, 1965), copulation (Caggiula, 1970; Caggiula and Hoebel, 1966), or predatory attack (Hutchinson and Renfrew, 1966; Wasman and Flynn, 1962). While dozens of fiber systems are intermingled in the MFB (Nieuwenhuys et al, 1982), several lines of evidence suggest that only a small subset of MFB fibers mediates the drive-like effects, on the 


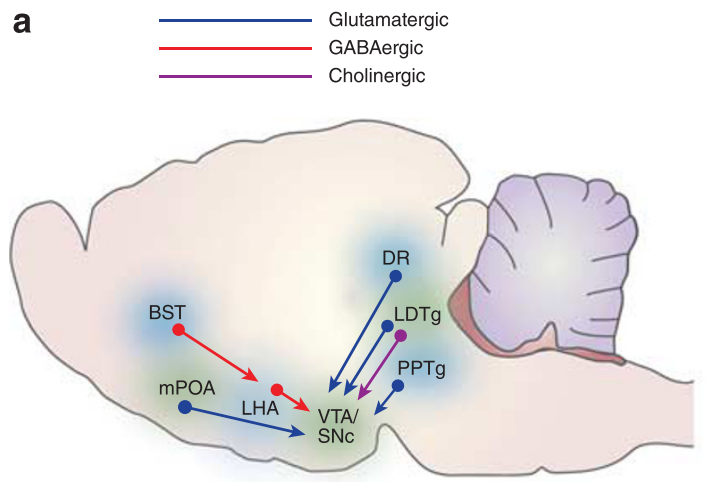

b

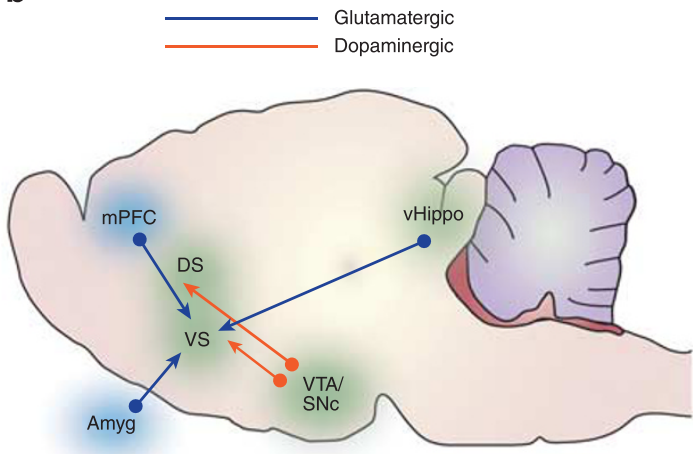

Figure I Reinforcing and drive-like input pathways to the ventral tegmental area (a) and striatum (b), confirmed by optogenetic studies. Amyg: amygdala; BST: bed nucleus of the stria terminalis; DR: dorsal raphe; DS: dorsal striatum; LDTg: latero-dorsal tegmental nucleus; LHA: lateral hypothalamic area; mPFC: medial prefrontal cortex; mPOA: medial preoptic area; PPTg: pedunculopontine tegmental area; SNc: substantia nigra, zona compacta; vHippo: ventral hippocampus; VS: ventral striatum; VTA: ventral tegmental area.

one hand, and the reinforcing effects on the other. First, feeding and copulation are not restricted to lateral hypothalamic stimulation sites; in each case they can be induced by ventral tegmental stimulation (Eibergen and Caggiula, 1973; Gratton and Wise, 1988a) and, for feeding at least, by stimulation at sites more caudal in the brainstem (Ball et al, 1974; Berntson, 1973a). Paired-pulse studies show that the fibers mediating lateral hypothalamic and VTA feeding and reinforcement have the same distributions of refractory periods, including the small contribution from ultrafast cholinergic elements (Gratton and Wise, 1985, Gratton and Wise, 1988b); have similar conduction velocities (Gratton and Wise, 1988a); and have common anatomical alignment between the lateral hypothalamic and ventral tegmental regions (Gratton and Wise, 1988a). These findings suggest, though they do not confirm, a common substrate.

Recent optogenetic studies extend this suggestion, identifying the lateral hypothalamic cells of origin and the neurochemical phenotype of both the feeding and reinforcement induced by MFB stimulation (Figure 1a). Photostimulation of lateral hypothalamic GABA cell bodies (Jennings et al, 2015) or their terminals in the VTA (Barbano et al, 2016; Gigante et al, 2016; Nieh et al, 2015) is reinforcing and causes feeding, apparently by disinhibiting the dopamine system through hyperpolarizing VTA GABA interneurons (Jennings et al, 2013; Nieh et al, 2016). While glutamatergic fibers also project from the lateral hypothalamus to the VTA, activating these fibers reduces dopamine release in the ventral striatum and is aversive (Jennings et al, 2013; Nieh et al, 2016). The fact that activation of descending fibers from the same origin, and with the same transmitter induce both feeding and reinforcement still does not confirm a common substrate, however. There appear to be at least two subpopulations of LH GABAergic neurons that participate in aspects of feeding and food-seeking (Jennings et al, 2015; Nieh et al, 2015) and they need not project to the same target.

Stimulation of glutamatergic lateral hypothalamic cell bodies or their projection to the lateral habenula is similarly aversive, and also inhibits feeding behavior in food-deprived animals (Jennings et al, 2015; Stamatakis et al, 2016).
GABAergic fibers from the bed nucleus of the stria terminalis project to and inhibit lateral hypothalamic glutamatergic neurons; stimulation of these neurons also induces feeding (Jennings et al, 2013; Kim et al, 2013). Similarly, a real-time place preference is produced using nonspecific stimulation of bed nucleus neurons projecting to the VTA, but not to the lateral hypothalamus or parabrachial nucleus (Kim et al, 2013).

Similar organizations have been recently reported in systems linking hypothalamic sites with copulation and social attachment. In the case of social attachment, a subset of preoptic area neurotensin-expressing neurons projects to dopaminergic neurons in the VTA; optogenetic stimulation of this system is reinforcing (Kempadoo et al, 2013; McHenry et al, 2017) and potentiates social approach (McHenry et al, 2017). Electrical stimulation studies also implicate the posterior hypothalamic area and the VTA in stimulation-induced reinforcement and copulation (Caggiula, 1970; Caggiula and Hoebel, 1966; Eibergen and Caggiula, 1973).

Dorsal raphe to VTA. Electrical stimulation of the dorsal (Simon et al, 1976) and median (Miliaressis et al, 1975; Simon et al, 1973) raphe nuclei and the region between them (Rompré and Miliaressis, 1985) can be strongly reinforcing, establishing responding at high rates for low levels of current (despite, in some cases, strong motor artifacts) (Rompré and Miliaressis, 1985). Dual-electrode paired-pulse experiments implicate fibers connecting these sites with reinforcement sites in the VTA, but the direction of conduction has not been determined (Boye and Rompre, 1996). Recent optogenetic stimulation studies now confirm that glutamatergic fibers projecting to the VTA originate in the dorsal raphe (Geisler et al, 2007), project to and make asymmetric synapses on dopaminergic neurons in the VTA (Qi et al, 2014), cause ventral tegmental dopamine release (Qi et al, 2014), and provide the substrate for the reinforcing effect of stimulation (Liu et al, 2014; McDevitt et al, 2014; Qi et al, 2014). The dorsal raphe nucleus contains additional GABAergic and dopaminergic cell types; stimulation of each cell type fails to reinforce behavior (Matthews et al, 2016; 
McDevitt et al, 2014). Serotonin appears not to contribute to reinforcement function itself (Fonseca et al, 2015; McDevitt et al, 2014; Miyazaki et al, 2014).

Laterodorsal and pedunculopontine tegmental nucleus projections to VTA. An ultrafast subpopulation of cholinergic fibers contributes to the reinforcing effects of MFB stimulation (Gratton and Wise, 1985). It is thought to do so by activating descending MFB fibers that continue through the VTA and synapse on cholinergic fibers projecting back to the dopamine system (Lester et al, 2010; Yeomans et al, 1985; Yeomans et al, 1993).

Nonselective optogenetic activation of VTA projections from laterodorsal tegmental nucleus (LDTg) is reinforcing (Lammel et al, 2012; Steidl and Veverka, 2015), as is selective activation of either cholinergic (Steidl et al, 2016; Xiao et al, 2016) or glutamatergic (Steidl et al, 2016; Yoo et al, 2016a) fibers from this region. Selective activation of cholinergic fibers caused real-time and conditioned preference for the chamber where stimulation had been experienced, whereas selective activation of glutamatergic fibers was reinforcing when fixed $1.5 \mathrm{~s}$ trains were earned by each entry, but not when self-controlled stimulation train durations were offered. Thus, cholinergic and glutamatergic activations were significantly different, with glutamatergic activation-like most forms of electrical stimulation-becoming aversive if allowed to persist. Stimulation of the cholinergic and glutamatergic pathways from LDTg also have different effects on dopamine cell firing and on locomotion, indicating that the two transmitters have some functions in common and some that differ.

Nose-poke activation of VTA projections from pedunculopontine tegmental nucleus is also reinforcing (Yoo et al, 2017); such stimulation is most effective at 30 or $40 \mathrm{~Hz}$, a frequency range not usually tested in the early optical selfstimulation tests. Stimulation at $20 \mathrm{~Hz}$ caused real-time but not conditioned place preferences (Xiao et al, 2016).

Lateral habenula projections to VTA and rostromedial tegmental nucleus. Nonselective optogenetic activation of lateral habenula projections that target neurons in the VTA (Lammel et al, 2012) or target the adjacent rostromedial tegmental nucleus (Stamatakis and Stuber, 2012) are aversive.

\section{Afferents to the Striatum}

The striatum receives input from several structures, including cortex, amygdala, thalamus, and hippocampus. The striatum is divided into dorsal and ventral compartments; electrical stimulation is reinforcing in each region (Figure 1b). A notable difference in afferent inputs between these two regions is that the dorsal striatum receives input from prefrontal, motor, and sensory cortices, whereas cortical inputs to the ventral striatum are limited primarily to the prefrontal cortex. Paired-pulse, dual-electrode studies have confirmed linkage between medial prefrontal cortical and dorsal striatal reinforcement sites (Trzcińska and Bielajew, 1998). Inputs to dorsal striatum from this and other regions have not been tested for reinforcement in optogenetic studies.
Optogenetic activation of glutamatergic inputs from amygdala, hippocampus, and prefrontal cortex is reinforcing (Britt et al, 2012; Stuber et al, 2011). Only one thalamic site has been tested with optogenetic stimulation; activation of glutamatergic input from the paraventricular nucleus to the medial shell of nucleus accumbens is aversive (Zhu et al, 2016).

\section{Striatal Output Neurons}

The reinforcing effects of stimulation of the output neurons of the striatum are of particular interest. This is the only system implicated in the reinforcing function that is efferent to the dopamine system; the dopamine system is the primary system involved in reinforcement of synaptic connections (the stamping in of memory traces (Wise, 2004)). Electrical stimulation is moderately reinforcing in both the dorsal and ventral striatum, with relatively equal regional specificity across these regions (Prado-Alcala and Wise, 1984). The reinforcing effects are also of particular interest because the two types of striatal output neurons-nearly identical and approximately equal in number-perform seemingly opposite functions. Classically viewed, the $\mathrm{D}_{1} \mathrm{R}$-mediated responses are thought to activate behavior and the $\mathrm{D}_{2} \mathrm{R}$ mediated responses are thought to inhibit behavior (Kravitz et al, 2010).

There are two output pathways in the striatum. In the dorsal striatum, optogenetic stimulation of the direct output pathway (projects directly to substantia nigra, pars reticulata) is clearly reinforcing, establishing lever-pressing or touchplate contacts relative to unstimulated control contacts (Kravitz et al, 2012; Vicente et al, 2016), and increasing the amount of time an animal spends in a stimulation-associated test area (Kravitz et al, 2012). Activation of direct pathway neurons also established a conditioned preference for the environment where it had been previously received (Kravitz et al, 2012). Response habits were learned quickly, within a few minutes with an easy access task (Kravitz et al, 2012) and within a few days on a difficult task (Vicente et al, 2016).

Stimulation of the indirect pathway was initially avoided (Kravitz et al, 2012) or neutral (Vicente et al, 2016), but this effect was short-lived; over the course of 4 weeks of testing, mice developed a significant, though weak, preference for activation of the $\mathrm{D}_{2} \mathrm{R}$ system (Vicente et al, 2016). This indirect pathway response was unusual in that the animals learned to press the inactive lever to almost the same extent as they pressed the active lever, showing marginal discrimination between the physically identical levers. The behaviors activated by indirect pathway stimulation were different from those caused by direct pathway stimulation, although simple tests like forward $v$ s backward locomotion were not reported. The current assumption is that indirect pathway stimulation activates behaviors like postural stability, necessary for discrete direct pathway actions (Cui et al, 2013; Tecuapetla et al, 2016; Vicente et al, 2016).

In the ventral striatum, the effects of optogenetic stimulation reveal greater complications. When the ventral section of the structure was globally stimulated, the effect was reinforcing in both real-time preference and nose-poke tasks (Britt et al, 2012). However, in a follow-up experiment targeting direct pathway (dynorphin-expressing neurons), it was found that stimulation in the dorsal portion was 
reinforcing, whereas stimulation in the ventral portion was aversive (Al-Hasani et al, 2015). Direct pathway neurons coexpress the peptide co-transmitter dynorphin, a kappa opioid agonist, and both the rewarding or the aversive effects of stimulating this pathway were antagonized by a local infusion of a kappa-opioid antagonist; in separate trials, rewarding and aversive effects could be demonstrated in each animal (Al-Hasani et al, 2015).

The effect of kappa receptor antagonism raises several questions. First, because the kappa opioid receptor is expressed by several local neuronal subtypes-local neurons, incoming terminals, and recurrent collaterals (Carlezon and Krystal, 2016; Svingos et al, 1999; Tejeda et al, 2017) - it is not clear what kappa population or populations are crucial for the optogenetic effects. That the motivational effects of $\mathrm{D}_{1} \mathrm{R}$ neurons can be blocked by the accumbens release of a peptide co-transmitter raises the important issue of which functions are controlled locally and which are controlled by the release of neurotransmitters from the distant terminals of these long-axon projections. Moreover, while dorsal-ventral differences have been identified, rostral-caudal differences are also suspected to have different motivational functions (Reynolds and Berridge, 2002). Finally, the findings with ventral striatal stimulation must raise the question of localized specialization within the dorsal striatum.

\section{MOTIVATION AND REINFORCEMENT: CORE CIRCUIT ELEMENTS}

The reviewed studies suggest an expanded core framework for reinforcement circuitry, a portion of which is also implicated in drive-like effects. In addition, the core elements include varieties of input-to and output-from the regions of the dopaminergic cell groups and their terminal fields in the striatum, regions where addictive drug exposure is known to cause neuroadaptations associated with compulsive drug habits. One of the inputs to the region of the dopamine cell bodies-the GABAergic input from the LHA - is implicated in both reinforcement and food-associated drive function.

\section{SITES FOR FUTURE STUDY}

Of obvious interest for further study are sites identified as motivational sites by early electrical stimulations studies. The variety of such sites-some clearly in presumed sensory areas and some in arguably motor areas-suggests a broader variety of reinforcement substrates and perhaps a deeper understanding of motivation itself. This includes sites in the brainstem where feeding and reinforcement can each be induced as well as sites all over the brain where stimulation is reinforcing (Figure 2). The study of a wider range of sites should improve our understanding of reinforcement in general.

\section{Dorsal Pons and Deep Cerebellar Nuclei}

Feeding and reinforcement can each be induced by electrical stimulation of sites caudal to the VTA. An important possibility is that these sites may be along caudal extensions of the MFB. The dorsal midbrain sites have been most extensively documented and fall along the path of (but not

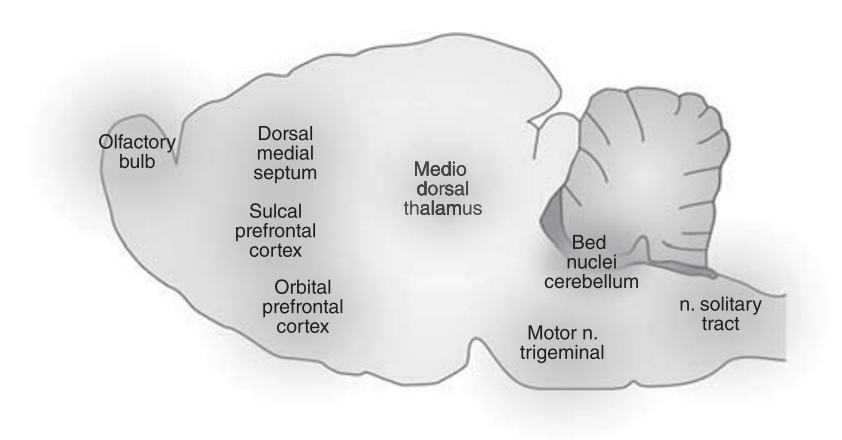

Figure 2 A variety of reinforcement-related regions identified in electrical stimulation studies but not yet tested in optogenetic studies.

directly in) the caudal portions of the superior cerebellar peduncle, extending to the deep cerebellar nuclei (Ball et al, 1974; Berntson, 1973b; Corbett et al, 1982; Micco, 1974). Biting attack can also be induced by stimulation near these sites (Berntson, 1973a). Optogenetic methods would be ideal for testing the hypothesis that these additional sites are a caudal extension of the MFB (Berntson and Micco, 1976); these dorsal tegmental sites are the only brainstem sites that, like the diencephalic MFB, seem involved in both drive and reinforcement. On the other hand, these sites may identify rostrally projecting fibers, perhaps synapsing in the VTA.

\section{Other Brainstem Sites for Feeding or Reinforcement}

Feeding can also be induced by stimulation of sites in the lateral and ventrolateral medulla of the cat (Berntson and Hughes, 1974), near the region of the motor nucleus of the trigeminal where stimulation is reinforcing in the rat (Van Der Kooy and Phillips, 1977; van der Kooy and Phillips, 1979). Electrical stimulation of the dorsal medulla, in the region of the nucleus of the solitary tract is reinforcing (Carter and Phillips, 1975), and this nucleus is a relay for sweet taste (Blomquist and Antem, 1965), a primary reinforcing sensory stimulus (Pfaffmann, 1960). Cells of origin or projections have not been identified.

\section{Other Forebrain Sites}

Feeding can be induced by stimulation of a variety of forebrain sites in the monkey, including the medial thalamus, anterior cingulate, septal area, amygdala, internal capsule, putamen, and stria medullaris (Milgram et al, 1977; Robinson and Mishkin, 1962,1968). Numerous thalamic sites have been found reinforcing in rats, with particular reinforcement sensitivity identified in the stria medullaris and the junction of the paratenial and centromedial nuclei (Sutherland and Nakajima, 1981; Vachon and Miliaressis, 1992). Electrical stimulation of the dorsal hippocampus is reinforcing (Campbell et al, 1978) and this is facilitated by food deprivation (Milgram et al, 1977); feeding is induced by dorsal hippocampal stimulation but follows offset rather than onset of stimulation (Milgram et al, 1977). Electrical stimulation of the olfactory bulb is reinforcing in the rat (Phillips and Mogenson, 1969), and this effect is enhanced by reinforcing odor stimuli (Phillips, 1970). 


\section{SUMMARY AND CONCLUSIONS}

Converging evidence from electrical and optogenetic brain stimulation studies implicates the long-axon forebrain dopamine systems and some of their afferents and one of their efferent targets (along with some of their inputs) in motivational function. Evidence from electrical stimulation studies also implicates fibers from several seemingly unrelated structures that remain to be studied with optogenetic techniques that can be used to identify cells of origin, neurotransmitters, and projection targets. Further study with optogenetic methods offers a method for elaborating and limiting the motivational circuitry first suggested by electrical stimulation. Of particular interest will be anatomical linkages between these electrical stimulation sites and the core motivational systems that optogenetics is establishing. These stimulation studies, linked to recording studies and loss-of-function studies, promise a broader understanding of the complex circuitry linking sensory and motor functions in behavior.

\section{FUNDING AND DISCLOSURE}

The authors were supported by the Intramural Research Program, National Institute on Drug Abuse. The authors declare no conflict of interest.

\section{REFERENCES}

Al-Hasani R, McCall JG, Shin G, Gomez AM, Schmitz GP, Bernardi JM et al (2015). Distinct subpopulations of nucleus accumbens dynorphin neurons drive aversion and reward. Neuron 87: 1063-1077.

Andersson B, Wyrwicka W (1957). The elilcitation of a drinking motor conditioned reaction by electrical stimulation of the hypothalamic 'drinking area' in the goat. Acta Physiol Scand 41: 194-198.

Annau Z, Heffner R, Koob GF (1974). Electrical self-stimulation of single and multiple loci: long term observations. Physiol Behav 13: 281-290.

Ball GG, Micco DJ, Berntson GG (1974). Cerebellar stimulation in the rat: complex stimulation-bound oral behaviors and selfstimulation. Physiol Behav 13: 123-127.

Barbano MF, Wang H-L, Morales M, Wise RA (2016). Feeding and reward are differentiallly induced by activating GABAergic lateral hypothalamic projections to VTA. J Neurosci 336: 2975-2985.

Berntson GG (1973a). Attack, grooming, and threat elicited by stimulation of the pontine tegmentum in cats. Physiol Behav 11: 81-87.

Berntson GG (1973b). Evidence for higher functions of the cerebellum: eating and grooming elicited by cerebellar stimulation in cats. Proc Natl Acad Sci USA 70: 2497-2499.

Berntson GG, Hughes HC (1974). Medullary mechanisms for eating and grooming behaviors in the cat. Exp Neurol 44: 255-265.

Berntson GG, Micco DJ (1976). Organization of brainstem behavioral systems. Brain Res Bull 1: 471-483.

Bielajew C, Shizgal P (1982). Behaviorally derived measures of conduction velocity in the substrate for rewarding medial forebrain bundle stimulation. Brain Res 237: 107-119.

Bielajew C, Shizgal P (1986). Evidence implicating descending fibers in self-stimulation of the medial forebrain bundle. J Neurosci 6: 919-929.

Blomquist AJ, Antem A (1965). Localization of the terminals of the tongue afferents in the nucleus of the solitary tract. J Comp Neurol 124: $127-130$.
Bower GH, Miller NE (1958). Rewarding and punishing effects from stimulating the same place in the rat's brain. J Comp Physiol Psychol 51: 69-72.

Boye SM, Rompre PP (1996). Mesencephalic substrate of reward: axonal connections. J Neurosci 16: 3511-3520.

Britt JP, Benaliouad F, McDevitt RA, Stuber GD, Wise RA, Bonci A (2012). Synaptic and behavioral profile of multiple glutamatergic inputs to the nucleus accumbens. Neuron 76: 790-803.

Caggiula AR (1970). Analysis of the copulation-reward properties of posterior hypothalamic stimulation in male rats. J Comp Physiol Psychol 70: 388-412.

Caggiula AR, Hoebel B (1966). Copulation-reward site in the posterior hypothalamus. Science 153: 1284-1285.

Campbell KA, Milgram NW, Christoff JK (1978). Plasticity in the reinforcing consequences of hippocampal stimulation. Brain Res 159: 458-462.

Carlezon WA Jr, Krystal AD (2016). Kappa-opioid antagonists for psychiatric disorders: from bench to clinical trials. Depress Anxiety 33: 895-906.

Carr KD (1996). Feeding, drug abuse, and the sensitization of reward by metabolic need. Neurochem Res 21: 1455-1467.

Carter DA, Phillips AG (1975). Intracranial self-stimulation at sites in the dorsal medulla oblongata. Brain Res 94: 155-160.

Chuhma N, Mingote S, Moore H, Rayport S (2014). Dopamine neurons control striatal cholinergic neurons via regionally heterogeneous dopamine and glutamate signaling. Neuron 81: 901-912.

Coons EE, Cruce JA (1968). Lateral hypothalamus: food current intensity in maintaining self-stimulation of hunger. Science 159: 1117-1119.

Corbett D, Fox E, Milner PM (1982). Fiber pathways associated with cerebellar self-stimulation in the rat: a retrograde and anterograde tracing study. Behav Brain Res 6: 167-184.

Corbett D, Wise RA (1980). Intracranial self-stimulation in relation to the ascending dopaminergic systems of the midbrain: a moveable electrode mapping study. Brain Res 185: 1-15.

Cox V, Valenstein ES (1969). Distribution of hypothalamic sites yielding stimulus bound behavior. Brain Behav Evol 2: 359-376.

Crow TJ (1972). A map of the rat mesencephalon for electrical selfstimulation. Brain Res 36: 265-273.

Cui G, Jun SB, Jin X, Pham MD, Vogel SS, Lovinger DM et al (2013). Concurrent activation of striatal direct and indirect pathways during action initiation. Nature 494: 238-242.

Darvas M, Wunsch AM, Gibbs JT, Palmiter RD (2014). Dopamine dependency for acquisition and performance of Pavlovian conditioned response. Proc Natl Acad Sci USA 111: 2764-2769.

Delgado JM, Anand BK (1953). Increase of food intake induced by electrical stimulation of the lateral hypothalamus. Am J Physiol 172: $162-168$.

Deutsch JA, Howarth CI, Ball GC, Deutsch D (1962). Threshold differentiation of drive and reward in the Olds effect. Nature 196: 699-700.

Dobi A, Margolis EB, Wang HL, Harvey BK, Morales M (2010). Glutamatergic and nonglutamatergic neurons of the ventral tegmental area establish local synaptic contacts with dopaminergic and nondopaminergic neurons. J Neurosci 30: 218-229.

Eibergen RD, Caggiula AR (1973). Ventral midbrain involvement in copulatory behavior of the male rat. Physiol Behav 10: $435-441$.

Fonseca MS, Murakami M, Mainen ZF (2015). Activation of dorsal raphe serotonergic neurons promotes waiting but is not reinforcing. Curr Biol 25: 306-315.

Fouriezos G, Hansson P, Wise RA (1978). Neuroleptic-induced attenuation of brain stimulation reward in rats. J Comp Physiol Psychol 92: 661-671.

Fouriezos G, Wise RA (1976). Pimozide-induced extinction of intracranial self-stimulation: response patterns rule out motor or performance deficits. Brain Res 103: 377-380. 
Franklin KBJ, McCoy SN (1979). Pimozide-induced extinction in rats: stimulus control of responding rules out motor deficit. Pharmacol Biochem Behav 11: 71-75.

Fulton S, Woodside B, Shizgal P (2000). Modulation of brain reward circuitry by leptin. Science 287: 125-128.

Fulton S, Woodside B, Shizgal P (2006). Potentiation of brain stimulation reward by weight loss: evidence for functional heterogeneity in brain reward circuitry. Behav Brain Res 174: 56-63.

Gallistel CR, Boytim M, Gomita Y, Klebanoff L (1982). Does pimozide block the reinforcing effect of brain stimulation? Pharmacol Biochem Behav 17: 769-781.

Gallistel CR, Shizgal P, Yeomans J (1981). A portrait of the substrate for self-stimulation. Psychol Rev 88: 228-273.

Geisler S, Derst C, Veh RW, Zahm DS (2007). Glutamatergic afferents of the ventral tegmental area in the rat. $J$ Neurosci 27: 5730-5743.

Gigante ED, Benaliouad F, Zamora-Olivencia V, Wise RA (2016). Optogenetic activatin of a lateral hypothalamic-ventral tegmental drive-reward pathway. PLOS ONE 11: e0158885.

Gratton A, Wise RA (1985). Hypothalamic reward mechanism: two first-stage fiber populations with a cholinergic component. Science 227: 545-548.

Gratton A, Wise RA (1988a). Comparisons of connectivity and conduction velocities for medial forebrain bundle fibers subserving stimulation-induced feeding and brain stimulation reward. Brain Res 438: 264-270.

Gratton A, Wise RA (1988b). Comparisons of refractory periods for medial forebrain bundle fibers subserving stimulation-induced feeding and brain stimulation reward: a psychophysical study. Brain Res 438: 256-263.

Greer MA (1955). Suggestive evidence of a primary drinking center in hypothalamus of the rat. Proc Soc Exp Biol Med 89: 59-62.

Hess WR (1957). The Functional Organization of the Diencephalon. Grune \& Stratton: New York, NY, USA.

Hnasko TS, Hjelmstad GO, Fields HL, Edwards RH (2012). Ventral tegmental area glutamate neurons: electrophysiological properties and projections. J Neurosci 32: 15076-15085.

Hodos W (1964). The nonaversive properties of long durations of rewarding brain stimulatin. Am Psychol 18: 437.

Hodos W (1965). Motivational properties of long durations of rewarding brain stimulation. J Comp Physiol Psychol 59: 219-224.

Huston JP (1971). Relationship between motivating and rewarding stimulation of the lateral hypothalamus. Physiol Behav 6: 711-716.

Hutchinson RR, Renfrew JW (1966). Stalking attack and eating behaviors elicited from the same sites in the hypothalamus. J Comp Physiol Psychol 61: 360-367.

Ikemoto S, Glazier BS, Murphy JM, McBride WJ (1997). Role of dopamine $\mathrm{D} 1$ and $\mathrm{D} 2$ receptors in the nucleus accumbens in mediating reward. J Neurosci 17: 8580-8587.

Ilango A, Kesner AJ, Broker CJ, Wang DV, Ikemoto S (2014a). Phasic excitation of ventral tegmental dopamine neurons potentiates the initiation of conditioned approach behavior: parametric and reinforcement-schedule analyses. Front Behav Neurosci 8: 155.

Ilango A, Kesner AJ, Keller KL, Stuber GD, Bonci A, Ikemoto S (2014b). Similar roles of substantia nigra and ventral tegmental dopamine neurons in reward and aversion. J Neurosci 34: 817-822.

Jennings JH, Rizzi G, Stamatakis AM, Ung RL, Stuber GD (2013). The inhibitory circuit architecture of the lateral hypothalamus orchestrates feeding. Science 341: 1517-1521.

Jennings JH, Ung RL, Resendez SL, Stamatakis AM, Taylor JG, Huang J et al (2015). Visualizing hypothalamic network dynamics for appetitive and consummatory behaviors. Cell 160: 516-527.

Kawano M, Kawasaki A, Sakata-Haga H, Fukui Y, Kawano H, Nogami $\mathrm{H}$ et al (2006). Particular subpopulations of midbrain and hypothalamic dopamine neurons express vesicular glutamate transporter 2 in the rat brain. J Comp Neurol 498: 581-592.

Kempadoo KA, Tourino C, Cho SL, Magnani F, Leinninger GM, Stuber GD et al (2013). Hypothalamic neurotensin projections promote reward by enhancing glutamate transmission in the VTA. J Neurosci 33: 7618-7626.

Kim KM, Baratta MV, Yang A, Lee D, Boyden ES, Fiorillo CD (2012). Optogenetic mimicry of the transient activation of dopamine neurons by natural reward is sufficient for operant reinforcement. PLoS ONE 7: e33612.

Kim SY, Adhikari A, Lee SY, Marshel JH, Kim CK, Mallory CS et al (2013). Diverging neural pathways assemble a behavioural state from separable features in anxiety. Nature 496: 219-223.

Kravitz AV, Freeze BS, Parker PR, Kay K, Thwin MT, Deisseroth K et al (2010). Regulation of parkinsonian motor behaviours by optogenetic control of basal ganglia circuitry. Nature 466: 622-626.

Kravitz AV, Tye LD, Kreitzer AC (2012). Distinct roles for direct and indirect pathway striatal neurons in reinforcement. Nat Neurosci 15: 816-818.

Lammel S, Lim BK, Ran C, Huang KW, Betley MJ, Tye KM et al (2012). Input-specific control of reward and aversion in the ventral tegmental area. Nature 491: 212-217.

Lammel S, Steinberg EE, Foldy C, Wall NR, Beier K, Luo L et al (2015). Diversity of transgenic mouse models for selective targeting of midbrain dopamine neurons. Neuron 85: 429-438.

Lester DB, Rogers TD, Blaha CD (2010). Acetylcholine-dopamine interactions in the pathophysiology and treatment of CNS disorders. CNS Neurosci Ther 16: 137-162.

Li X, Qi J, Yamaguchi T, Wang HL, Morales M (2013). Heterogeneous composition of dopamine neurons of the rat A10 region: molecular evidence for diverse signaling properties. Brain Struct Funct 218: 1159-1176.

Lippa AS, Antelman SM, Fisher AE, Canfield DR (1973). Neurochemical mediation of reward: a significant role for dopamine. Pharmacol Biochem Behav 1: 23-28.

Liu Z, Zhou J, Li Y, Hu F, Lu Y, Ma M et al (2014). Dorsal raphe neurons signal reward through 5-HT and glutamate. Neuron 81: $1360-1374$.

Margules DL, Olds J (1962). Identical "feeding" and "rewarding" systems in the lateral hypothalamus of rats. Science 135: 374-375.

Matthews GA, Nieh EH, Vander Weele CM, Halbert SA, Pradhan RV, Yosafat AS et al (2016). Dorsal raphe dopamine neurons represent the experience of social isolation. Cell 164: 617-631.

McDevitt RA, Tiran-Cappello A, Shen H, Balderas I, Britt JP, Marino RA et al (2014). Serotonergic versus nonserotonergic dorsal raphe projection neurons: differential participation in reward circuitry. Cell Rep 8: 1857-1869.

McHenry JA, Otis JM, Rossi MA, Robinson JE, Kosyk O, Miller NW et al (2017). Hormonal gain control of a medial preoptic area social reward circuit. Nat Neurosci 20: 449-458.

Mendelson J (1970). Self-induced drinking in rats: the qualitative identity of drive and reward systems in the lateral hypothalamus. Physiol Behav 5: 925-930.

Mendelson J, Freed WJ (1973). Do rats terminate hypothalamic stimulation only in order to turn it on again? Behav Biol 8: 619-628.

Micco DJ (1974). Complex behaviors elicited by stimulation of the dorsal pontine tegmentum in rats. Brain Res 75: 172-176.

Milgram NW, Server AC, Campbell KA (1977). Effect of food and water deprivation on hippocampal self-stimulation and poststimulation feeding. Physiol Psychol 5: 43-48.

Miliaressis E, Bouchard A, Jacobowitz DM (1975). Strong positive reward in median raphe: specific inhibition by para-chlorophenylalanine. Brain Res 98: 194-201.

Miyazaki KW, Miyazaki K, Tanaka KF, Yamanaka A, Takahashi A, Tabuchi S et al (2014). Optogenetic activation of dorsal raphe 
serotonin neurons enhances patience for future rewards. Curr Biol 24: 2033-2040.

Mogenson GJ, Stevenson JA (1966). Drinking and self-stimulation with electrical stimulation of the lateral hypothalamus. Physiol Behav 1: 251-254.

Muenzinger KF, Baxter LF (1957). The effects of training to approach vs. to escape from electric shock upon subsequent discrimination learning. J Comp Physiol Psychol 50: 252-257.

Nieh EH, Matthews GA, Allsop SA, Presbrey KN, Leppla CA, Wichmann $\mathrm{R}$ et al (2015). Decoding neural circuits that control compulsive sucrose seeking. Cell 160: 528-541.

Nieh EH, Vander Weele CM, Matthews GA, Presbrey KN, Wichmann R, Leppla CA et al (2016). Inhibitory input from the lateral hypothalamus to the ventral tegmental area disinhibits dopamine neurons and promotes behavioral activation. Neuron 90: $1286-1298$.

Nieuwenhuys R, Geeraedts MG, Veening JG (1982). The medial forebrain bundle of the rat. I. General introduction. J Comp Neurol 206: 49-81.

Olds J (1956). Runway and maze behavior controlled by basomedial forebrain stimulation in the rat. J Comp Physiol Psychol 49: $507-512$.

Olds J (1958a). Effects of hunger and male sex hormones on selfstimulation of the brain. J Comp Physiol Psychol 51: 320-324.

Olds J (1958b). Satiation effects in self-stimulation of the brain. J Comp Physiol Psychol 51: 675-678.

Olds J (1960). Approach-avoidance dissociations in rat brain. Am J Physiol 199: 965-968.

Olds J, Milner P (1954). Positive reinforcement produced by electrical stimulation of septal area and other regions of rat brain. J Comp Physiol Psychol 47: 419-427.

Olds J, Travis RP, Schwing RC (1960). Topographic organization of hypothalamic self-stimulation functions. J Comp Physiol Psychol 53: 23-32.

Olds ME, Olds J (1963). Approach-avoidance analysis of rat diencephalon. J Comp Neurol 120: 259-295.

Pascoli V, Terrier J, Hiver A, Luscher C (2015). Sufficiency of mesolimbic dopamine neuron stimulation for the progression to addiction. Neuron 88: 1054-1066.

Pfaffmann C (1960). The pleasures of sensation. Psychol Rev 67: 253-268.

Phillips AG (1970). Enhancement and inhibition of olfactory bulb self-stimulation by odours. Physiol Behav 5: 1127-1131.

Phillips AG, Mogenson GJ (1969). Self-stimulation of the olfactory bulb. Physiol Behav 4: 195-197.

Phillips AG, Nikaido R (1975). Disruption of brain-stimulationinduced feeding by dopamine receptor blockade. Nature 258: 750-751.

Prado-Alcala R, Wise RA (1984). Brain stimulation reward and dopamine terminal fields. I. Caudate- putamen, nucleus accumbens and amygdala. Brain Res 297: 265-273.

Qi J, Zhang S, Wang H-L, Wang H, de Jesus Aceves Buendia J, Hoffman AF et al (2014). A glutamatergic reward input from the dorsal raphe to ventral tegmental area dopamine neurons. Nat Commun 5: 5390.

Qi J, Zhang S, Wang HL, Barker DJ, Miranda-Barrientos J, Morales M (2016a). VTA glutamatergic inputs to nucleus accumbens drive aversion by acting on GABAergic interneurons. Nat Neurosci 19: 725-733.

Qi J, Zhang S, Wang HL, Barker DJ, Miranda-Barrientos J, Morales M (2016b). VTA glutamatergic inputs to nucleus accumbens drive aversion by acting on GABAergic interneurons. Nat Neurosci 19: 725-733.

Ranck JB Jr (1975). Which elements are excited in electrical stimulation of mammalian central nervous system: a review. Brain Res 98: 417-440.

Reynolds SM, Berridge KC (2002). Positive and negative motivation in nucleus accumbens shell: bivalent rostrocaudal gradients for
GABA-elicited eating, taste "liking"/"disliking" reactions, place preference/avoidance, and fear. J Neurosci 22: 7308-7320.

Roberts WW (1958a). Both rewarding and punishing effects from stimulation of posterior hypothalamus of cat with same electrode at same intensity. J Comp Physiol Psychol 51: 400-407.

Roberts WW (1958b). Rapid escape learning without avoidance learning motivated by hypothalamic stimulation in cats. J Comp Physiol Psychol 51: 391-399.

Roberts WW, Carey RJ (1965). Rewarding effect of performance of gnawing aroused by hypothalamic stimulation in the rat. J Comp Physiol Psychol 59: 317-324.

Robinson BW, Mishkin M (1962). Alimentary responses evoked from forebrain structures in Macaca mulatta. Science 136: 260-262.

Robinson BW, Mishkin M (1968). Alimentary responses to forebrain stimulation in monkeys. Exp Brain Res 4: 330-366.

Rompré P-P, Miliaressis E (1985). Pontine and mesencephalic substrates of self-stimulation. Brain Res 359: 246-259.

Root DH, Mejias-Aponte CA, Qi J, Morales M (2014a). Role of glutamatergic projections from ventral tegmental area to lateral habenula in aversive conditioning. J Neurosci 34: 13906-13910.

Root DH, Mejias-Aponte CA, Zhang S, Wang HL, Hoffman AF, Lupica CR et al (2014b). Single rodent mesohabenular axons release glutamate and GABA. Nat Neurosci 17: 1543-1551.

Root DH, Wang HL, Liu B, Barker DJ, Mod L, Szocsics P et al (2016). Glutamate neurons are intermixed with midbrain dopamine neurons in nonhuman primates and humans. Sci Rep 6: 30615 .

Rossi MA, Sukharnikova T, Hayrapetyan VY, Yang L, Yin $\mathrm{HH}$ (2013). Operant self-stimulation of dopamine neurons in the substantia nigra. PLoS ONE 8: e65799.

Routtenberg A, Malsbury C (1969). Brainstem pathways of reward. J Comp Physiol Psychol 68: 22-30.

Shizgal P, Bielajew C, Corbett D, Skelton R, Yeomans J (1980). Behavioral methods for inferring anatomical linkage between rewarding brain stimulation sites. J Comp Physiol Psychol 94: 227-237.

Simon H, Le Moal M, Cardo B (1976). Intracranial self-stimulation from the dorsal raphe nucleus of the rat: effects of the injection of para-chlorophenylalanine and of alpha-methylparatyrosine. Behav Biol 16: 352-364.

Simon H, LeMoal M, Cardo B (1973). Mise en evidence du comportement d'autostimulation dans le noyau raphe median du rat. C R Acad Sci 277: 591-593.

Stamatakis AM, Jennings JH, Ung RL, Blair GA, Weinberg RJ, Neve $\mathrm{RL}$ et al (2013). A unique population of ventral tegmental area neurons inhibits the lateral habenula to promote reward. Neuron 80: 1039-1053.

Stamatakis AM, Stuber GD (2012). Activation of lateral habenula inputs to the ventral midbrain promotes behavioral avoidance. Nat Neurosci 15: 1105-1107.

Stamatakis AM, Van Swieten M, Basiri ML, Blair GA, Kantak P, Stuber GD (2016). Lateral hypothalamic area glutamatergic neurons and their projections to the lateral habenula regulate feeding and reward. $J$ Neurosci 36: 302-311.

Stauffer WR, Lak A, Yang A, Borel M, Paulsen O, Boyden ES et al (2016). Dopamine neuron-specific optogenetic stimulation in Rhesus macaques. Cell 166: 1564-1571.e1566.

Steidl S, Veverka K (2015). Optogenetic excitation of LDTg axons in the VTA reinforces operant responding in rats. Brain Res 1614: 86-93.

Steidl S, Wang H, Ordonez M, Zhang S, Morales M (2016). Optogenetic excitation in the ventral tegmental area of glutamatergic or cholinergic inputs from the laterodorsal tegmental area drives reward. Eur J Neurosci 45: 559-571.

Steinberg EE, Boivin JR, Saunders BT, Witten IB, Deisseroth K, Janak PH (2014). Positive reinforcement mediated by midbrain 
dopamine neurons requires $\mathrm{D} 1$ and $\mathrm{D} 2$ receptor activation in the nucleus accumbens. PLoS ONE 9: e94771.

Steiner SS, Beer B, Shaffer MM (1969). Escape from self-produced rates of brain stimulation. Science 163: 90-91.

Stuber GD, Britt JP, Bonci A (2011). Optogenetic modulation of neural circuits that underlie reward seeking. Biol Psychiatry 71: 1061-1067.

Sutherland RJ, Nakajima S (1981). Self-stimulation of the habenular complex in the rat. J Comp Physiol Psychol 95: 781-791.

Svingos AL, Colago EE, Pickel VM (1999). Cellular sites for dynorphin activation of kappa-opioid receptors in the rat nucleus accumbens shell. J Neurosci 19: 1804-1813.

Tecuapetla F, Jin X, Lima SQ, Costa RM (2016). Complementary contributions of striatal projection pathways to action initiation and execution. Cell 166: 703-715.

Tejeda HA, Wu J, Kornspun AR, Pignatelli M, Kashtelyan V, Krashes MJ et al (2017). Pathway- and cell-specific kappa-opioid receptor modulation of excitation-inhibition balance differentially gates D1 and D2 accumbens neuron activity. Neuron 93: 147-163.

Trzcińska M, Bielajew C (1998). Functional connections between medial prefrontal cortex and caudate-putamen in brainstimulation reward of rats. Behav Neurosci 112: 1177-1186.

Tsai HC, Zhang F, Adamantidis A, Stuber GD, Bonci A, de Lecea L et al (2009). Phasic firing in dopaminergic neurons is sufficient for behavioral conditioning. Science 324: 1080-1084.

Vachon MP, Miliaressis E (1992). Dorsal diencephalic selfstimulation: a movable electrode mapping study. Behav Neurosci 106: 981-991.

Van Der Kooy D, Phillips AG (1977). Trigeminal substrates of intracranial self-stimulation. Science 196: 447-449.

van der Kooy D, Phillips AG (1979). Involvement of the trigeminal motor system in brain stem self-stimulation and stimulationinduced behavior. Brain Behav Evol 16: 293-314.

Vicente AM, Galvao-Ferreira P, Tecuapetla F, Costa RM (2016). Direct and indirect dorsolateral striatum pathways reinforce different action strategies. Curr Biol 26: R267-R269.

Wang DV, Viereckel T, Zell V, Konradsson-Geuken A, Broker CJ, Talishinsky A et al (2017). Disrupting glutamate co-transmission does not affect acquisition of conditioned behavior reinforced by dopamine neuron activation. Cell Rep 18: 2584-2591.

Wang HL, Qi J, Zhang S, Wang H, Morales M (2015). Rewarding effects of optical stimulation of ventral tegmental area glutamatergic neurons. J Neurosci 35: 15948-15954.

Wasman M, Flynn JP (1962). Directed attack elicited from the hypothalamus. Arch Neurol 6: 220-227.

Wise RA (1971). Individual differences in effects of hypothalamic stimulation: the role of stimulation locus. Physiol Behav 6: 569-572.

Wise RA (1980). Yes, but!...a response to Arbuthnott. Trends Neurosci 3: 200.

Wise RA (1981). Intracranial self-stimulation: mapping against the lateral boundaries of the dopaminergic cells of the substantia nigra. Brain Res 213: 190-194.

Wise RA (2002). Brain reward circuitry: insights from unsensed incentives. Neuron 36: 229-240.
Wise RA (2004). Dopamine, learning and motivation. Nat Rev Neurosci 5: 483-494.

Wise RA (2013). Dual roles of dopamine in food and drug seeking: the drive-reward paradox. Biol Psychiatry 73: 819-826.

Wise RA, Spindler J, deWit H, Gerber GJ (1978). Neurolepticinduced "anhedonia" in rats: pimozide blocks reward quality of food. Science 201: 262-264.

Witten IB, Lin SC, Brodsky M, Prakash R, Diester I, Anikeeva P et al (2010). Cholinergic interneurons control local circuit activity and cocaine conditioning. Science 330: 1677-1681.

Witten IB, Steinberg EE, Lee SY, Davidson TJ, Zalocusky KA, Brodsky $\mathrm{M}$ et al (2011). Recombinase-driver rat lines: tools, techniques, and optogenetic application to dopamine-mediated reinforcement. Neuron 72: 721-733.

Xiao C, Cho JR, Zhou C, Treweek JB, Chan K, McKinney SL et al (2016). Cholinergic mesopontine signals govern locomotion and reward through dissociable midbrain pathways. Neuron 90: 333-347.

Yamaguchi T, Wang HL, Li X, Ng TH, Morales M (2011). Mesocorticolimbic glutamatergic pathway. J Neurosci 31: 8476-8490.

Yamaguchi T, Wang HL, Morales M (2013). Glutamate neurons in the substantia nigra compacta and retrorubral field. Eur $J$ Neurosci 38: 3602-3610.

Yeomans JS (1979). Absolute refractory periods of self-stimulation neurons. Physiol Behav 22: 911-919.

Yeomans JS (1982). The cells and axons mediating medial forebrain bundle reward. In: Hoebel BG, Novin D (eds). The Neural Basis of Feeding and Reward. Haer Institute: Brunswick, ME, USA. pp 405-417.

Yeomans JS (1989). Two substrates for medial forebrain bundle selfstimulation: myelinated axons and dopamine axons. Neurosci Biobehav Rev 13: 91-98.

Yeomans JS, Kofman O, McFarlane V (1985). Cholinergic involvement in lateral hypothalamic rewarding brain stimulation. Brain Res 329: 19-26.

Yeomans JS, Maidment NT, Bunney BS (1988). Excitability properties of medial forebrain bundle axons of A9 and A10 dopamine cells. Brain Res 450: 86-93.

Yeomans JS, Mathur A, Tampakeras M (1993). Rewarding brain stimulation: role of tegmental cholinergic neurons that activate dopamine neurons. Behav Neurosci 107: 1077-1087.

Yoo JH, Zell V, Gutierrez-Reed N, Wu J, Ressler R, Shenasa MA et al (2016a). Ventral tegmental area glutamate neurons co-release GABA and promote positive reinforcement. Nat Commun 7: 13697.

Yoo JH, Zell V, Gutierrez-Reed N, Wu J, Ressler R, Shenasa MA et al (2016b). Ventral tegmental area glutamate neurons corelease GABA and promote positive reinforcement. Nat Commun 7: 13697.

Yoo JH, Zell V, Wu J, Punta C, Ramajayam N, Shen X et al (2017). Activation of pedunculopontine glutamate neurons is reinforcing. I Neurosci 37: 38-46.

Zhu Y, Wienecke CF, Nachtrab G, Chen X (2016). A thalamic input to the nucleus accumbens mediates opiate dependence. Nature 530: 219-222. 